\title{
Marital status and survival analysis of patients with pure mucinous breast carcinoma: A SEER Population-Based Retrospective study
}

\section{Fan Tang}

Guangzhou University of Chinese Medicine

\section{Xiaoqing Wei}

Guangzhou University of Chinese Medicine

\section{Liping Dian}

Guangzhou University of Chinese Medicine

\section{Rui Xu}

Guangdong Provincial Hospital of Chinese Medicine

\section{Liping Ren}

Guangdong Provincial Hospital of Chinese Medicine

\section{Quzhi Zhou}

Guangdong Provincial Hospital of Chinese Medicine

\section{Qianjun Chen}

Guangdong Provincial Hospital of Chinese Medicine

\section{Yuzhu Zhang ( $\nabla$ z.yz1012@163.com )}

Guangdong Provicial Hospital of Chinese Medicine https://orcid.org/0000-0002-7010-3537

\section{Primary research}

Keywords: Pure mucinous breast carcinoma, Marital status, SEER, Prognosis

Posted Date: February 26th, 2020

DOI: https://doi.org/10.21203/rs.2.24637/v1

License: (c) (i) This work is licensed under a Creative Commons Attribution 4.0 International License. Read Full License 


\section{Abstract}

Background The present study was conducted to investigate the influence of marital status on survival of pure mucinous breast carcinoma based on surveillance, epidemiology, and end results (SEER) databases.

Methods Data were extracted from the SEER database on eligible patients diagnosed with pure mucinous breast carcinoma between 1998 and 2015. Patients were divided into married groups and the not married groups. Survival curves were generated by the Kaplan-Meier method, and survival differences were estimated by using the Log-Rank test. Multivariate Cox Proportional Hazards Models was used to assess independent risk factors for survival.

Results A total of 14972 eligible pure mucinous breast carcinoma patients were enrolled from the SEER database, including 7462 (49.84\%) married and 7510 (50.16\%) not married patients. The OS and CSS were significantly greater in married patients than not married patients $(79.27 \mathrm{vs} 62.49 \%$ for OS and 96.07 vs $93.34 \%$ for $C S S$, both $P=0.000$ ). Among patients older than 75 , there were significantly more unmarried patients than married patients $(21.5 \%$ vs. $44.1 \%)$. Compared to the not married patients, cancer stage were even lower (stage I) (69.6\% vs. $62.6 \%)$, (stage II) ( $28.6 \%$ vs. $33.9 \%)$, (stage III) (0.6\% vs. $0.9 \%)$, (stage IV) (1.3\% vs. $2.5 \%)$, and more patients received breast conserving surgery (67.4\% vs. $62.9 \%)$, chemotherapy (15.3\% vs. $11.0 \%$ ) and radiation therapy ( $54.3 \%$ vs. $43.1 \%)$. Compared with the not married group, the proportion of non-recurrent lymph node metastasis was ( $82.8 \%$ vs. $74.6 \%$ ) (All P= 0.000 ). The Multivariate Cox Proportional Hazards Models showed that marriage is an independent protective factor for OS (HR =1.356, 95\% Cl: 1.271-1.446, $\mathrm{P}=0.000)$ and CSS ( $\mathrm{HR}=1.942,95 \% \mathrm{Cl}: 1.681-2.644, \mathrm{P}=0.000)$.

Conclusion Marital status was an independent prognostic indicator in pure mucinous breast carcinoma patients. Research data showed that married pure mucinous breast carcinoma patients can obtain better OS and CSS than the not married patients.

\section{Background}

Pure mucinous breast carcinoma $(\mathrm{PMBC})$, also known as colloid carcinoma, is a rare malignancy of the breast. According to the data reported, mucinous carcinoma(MC) account for between $1 \%$ and $6 \%$ of all breast cancers[1], while pure mucinous breast carcinoma account for only $0.9 \%$ to $2.2 \%$ of all breast cancers[2-3]. MC was first defined and described in 1826[4], and Silverberg et al.[5]were the first to quantify the number of diseased cells as the method of classifying the two groups, and MC was defined as having a mucinous component of at least $50 \%$. Since then, Rosen[6]developed diagnostic criteria of PMBC that lesions could not display high-grade histological features and with tumors composed of at least $90 \%$ mucin[7]. The population of patients with PMBC is mostly postmenopausal women, showing good clinical pathological characteristics, including lower incidence of lymph node metastasis, higher expression of estrogen and progesterone receptor (PR), and better cancer differentiation[8-9]. Therefore, $\mathrm{PMBC}$ was defined as a slow-growing tumor, for which the prognosis is somewhat better than that for MC and infiltrating ductal carcinoma (IDC)[10-12]. 
In past studies, many clinical features such as tumor size, TMN stage, cellularity, lymph node metastasis and an axillary staging by sentinel lymph node biopsy, have been studied and all been shown to be associated with PMBC tumor survival and prognosis[10,13], molecular phenotype, age, and receipt of chemotherapy and radiotherapy were also confirmed as the independent predictors of PMBC[14].

Not only that, people were starting to focus on the impact of social factors on the survival, development and prognosis of cancer patients. The quality of social support predicts better health related quality of life generally[15]. Among them, marital status has attracted wide attention as an important form of social common relations in modern society. Study has indicated that the not married patients were at greater risk of presentation with metastatic disease and cancer-specific mortality[16]. Marital status is considered to be an important factor affecting the survival and prognosis of cancer patients, which has been discussed in many literature, including small intestinal adenocarcinoma, colorectal cancer, lung cancer and other cancers[17-20]. For breast cancer patients, a number of studies also have shown that married breast cancer patients have better prognosis and survival outcomes than unmarried patients, and it is clear that marital status has become an independent factor affecting the survival prognosis of breast cancer patients[17, 21]. However, the influence of Marital status on the survival trend of PMBC patients has not been fully investigated.

To continue this in-depth study, we conducted this analytical study to explore the correlation between marital status and overall survival (OS) and cancer-specific survival (CSS) in PMBC patients, and whether the correlation varies with other factors such as age and cancer stage.

All of our data came from the Surveillance, Epidemiology, and End Results (SEER) program, which is closest to that representative as it provides population-based data from 18 Cancer Registries from population-based catchment areas related to cancer diagnoses, treatment and survival for approximately $30 \%$ of the U.S. population[23].

\section{Materials And Methods}

\section{Patients}

The data for this study were all from the SEER database (http://seer.cancer.gov). The unidentified data held by the SEER database were authorized to obtain, and we used SEER $\star$ Stat 8.3.6 software to extract eligible patients included in the database. A total of 21662 patients aged 18 or older who were diagnosed with pure mucinous breast carcinoma between 1998 and 2015 were included in the study. We conducted a series of screening exclusions for the patients initially included, and the inclusion criteria were referred as follows: 1) only one primary malignancy in their lifetime; 2 ) limited to the following histological types, according to the International Classification of Diseases for Oncology, 3rd Edition (ICD-0-3): mucinous adenocarcinoma (SEER histology codes 8480); 3) known marital status; 4) known stage (Breast Cancer Adjusted AJCC Cancer Staging Manual 6th Edition); 5) known surgery situation; 6) known survival months after diagnosis. Finally, we got a total of 14972 people who met the inclusion criteria. 


\section{Co-variables}

The main purpose of this study is to investigate the effect of marital status on survival outcomes of PBMC patients by comparing the incidence of OS and CSS in different marital states. OS is defined as the duration from tumor diagnosis to the most recent follow-up or date of death. CSS is defined as the duration from the diagnosis of the tumor to the latest follow-up or death from diagnosed PMBC.

Marital status is the main observation variable in this study, so we mainly divided the population into two groups for observation, namely the married group and the not married group. Married group was defined as married people including common law, and the single(never married), unmarried or domestic Partner $\square$ Divorced $\square$ Separated $\square$ Widowed were all considered disadvantaged in marital status and were therefore defined as not married groups.

\section{Statistical analysis}

The Chi-square test was used to compare the clinical characteristics of patients with different categories of marital status, and descriptive statistics were used to investigate the baseline characteristics of the patient population. The categorical variables are expressed as numbers with percentage ages. KaplanMeier method was used to calculate CSS and OS and generate the corresponding survival curve. The difference rate between groups was analyzed and calculated by Log-Rank test. For variables with statistically significant differences, Multivariate Cox Proportional Analysis was established to assess the effect of marital status on OS and CSS by calculating hazard ratios (HR) and their corresponding $95 \%$ confidence intervals $(\mathrm{Cl})$. A two-sided $\mathrm{P}<0.05$ was considered to be statistically significant. The analyses of statistics were conducted using SPSS (SPSS Inc., Chicago, USA, version 23).

\section{Results}

\section{Patient baseline characteristics}

Based on the inclusion criteria, we identified a total of 14972 patients with PMBC diagnosed between 1998 and 2015 in the SEER database. Specific inclusion and exclusion processes were detailed in Figure 1. All the patients were further divided into the married $(n=746249.84 \%)$ and the not married $(n=7510$ $50.16 \%$ ), and the baseline characteristics of the marital status of the two groups were shown in table 1. In terms of gender, the gender gap was too large to have any statistical significance. In other respects, For patients older than 75 years old, there were significantly more unmarried patients than married patients (aged $\geq 7521.5 \%$ vs. $44.1 \%$ ). Both the married group and the not married group showed low tumor differentiation and cancer grade, while the married group's cancer stage were even lower (stage I: $69.6 \%$ vs. $62.6 \%$ ), (stage II: $28.6 \%$ vs. $33.9 \%$ ), (stage III: $0.5 \%$ vs. $0.9 \%)$, (stage IV: $1.3 \%$ vs. $2.6 \%$ ). More married patients received breast conserving surgery (67.4\% vs. $62.9 \%)$, chemotherapy $(15.3 \%$ vs. $11.0 \%)$ and radiation therapy (54.3\% vs. $43.1 \%)$. The married group was also less likely to have recurrent lymph node metastases compared to unmarried ( $82.8 \%$ vs. $74.6 \%)$. All of which were statistically significant $(P<$ 0.001), as noted in Table 1. 


\section{Effects of marital status and other factors on OS and CSS of PMBC}

The overall patients were divided into the married group and the not married group, and the Kaplan-Meier curve was used to evaluate the OS and CSS of PMBC. The results showed that the OS and CSS were significantly greater in married patients than not married patients $(79.27$ vs $62.49 \%$ for OS and 96.07 vs 93.34\% for CSS). Meanwhile, by checking the Log-Rank tests, OS and BCSS were significantly higher in the married subgroup than in the not married group (Figure 2). Further Multivariate Cox Proportional Hazards Model showed that marital status, age, cancer stage, operation, and radiation therapy were independent prognostic factors associated with OS and CSS (Table 2 and 3 ). It turns out that for PMBC patients, both OS and BCSS in the not married group performed worse than those in the married group, while OS (HR=2.150, 95\% Cl: 2.020-2.288, $P<0.001)$ and CSS (HR=1.942, 95\% Cl: 1.681-2.244, $P<0.001)$.

For other factors, after uni-variate analysis by Cox Regression (Table 2 and 3 ), we found that: In the age group, with the increase of age, it is obvious that OS and CSS show worse results, with the age older than 75 years old, OS(HR=17.391, 95\% Cl: 9.038-33.464 $P<0.001)$ and CSS (HR=2.639, 95\% Cl: 1.249-5.576, $P$ $=0.011$ ). The same results were observed with regard to cancer stage, with both OS and CSS in PMBC patients showing poorer outcomes as the cancer grade increased: Take stage I as a reference, stage II OS (HR=1.415, 95\% Cl: 1.327-1.508 $P<0.001)$ and CSS(HR=2.590, 95\% Cl: 2.202-3.046 $P<0.001)$; stage III OS(HR=2.377, 95\% Cl: 1.802-3.137 $P<0.001)$ and CSS(HR=11.991, 95\% Cl: 8.181-17.576 $P<0.001)$; stage IV OS(HR=8.003, 95\% Cl: 6.965-9.196 $P<0.001)$ and CSS(HR=52.909, 95\% Cl: 43.693-64.068 $P<0.001)$. In terms of treatment, patients who choose breast-conserving surgery had better survival benefits than the others. Compared to patients who chose breast conserving surgery, mastectomy group OS(HR=1.339, 95\% Cl: 1.802-3.137 $P<0.001)$ and CSS(HR =11.991, 95\% Cl: 8.181-17.576 $P<0.001)$. Patients who choose radiotherapy can obviously get better OS and CSS, while without radiation therapy group OS(HR=2.193, 95\% Cl: $2.060-2.334 P<0.001)$ and CSS(HR =2.308, 95\% Cl: 1.989-2.677 $P<0.001)$. After Multivariate Cox Regression Analysis, we could also get the conclusion above (Table 2 and 3 ).

\section{Analysis of marital status at different stages in age subgroup}

In order to further explore the influence of marital status on the survival outcome of PMBC patients at different ages, we stratified all the included patients according to their ages and conducted Kaplan-Meier survival curve and Log-Rank test. Figure 3 shows Kaplan-Meier curve of OS rates in different ages: For PMBC patients aged over 45 years, the OS and CSS survival curves of the married group were both better than those of the not married group, all of which were $P \geq 0.001$, which were statistically significant. For patients aged $45-54$, the OS of the marrieds and the not marrieds were $93.27 \%$ vs $89.78 \%$; In age $55-64$ years old, the difference in survival outcome was most obvious in two marital states that the OS of the marrieds and the not marrieds were $89.07 \%$ vs $81.78 \%$; In aged $65-74$ years group, the OS of the marrieds and the not marrieds were $78.16 \%$ vs $70.28 \%$; And in aged older than 75 years group, the OS of the marrieds and the not marrieds were $52.09 \%$ vs $41.01 \%$. All the above results have been Log-Rank test: $P]$ 0.001 .

\section{Analysis of marital status at different stages in SEER stage subgroup}


We then assessed the effect of marital status on survival at each stage of the PMBC (Table 4). The results showed that marital status was an independent prognostic factor affecting survival and prognosis for PBMC patients with cancer stage I, II and IV $(P \leq 0.005)$. Since the sample size of stage III was too small $(\mathrm{N}=109)$, there was no statistical difference after examination. In each SEER stage, the OS rate of the married group and the not married group was $80.80 \%$ vs $65.81 \%$ (stage I), $78.18 \%$ vs $59.81 \%$ (stage II), $58.54 \%$ vs $50.00 \%$ (stage III), $29.17 \%$ vs $20.94 \%$ (stage IV); The CSS rate of the married group and the not married group was $97.75 \%$ vs $96.47 \%$ (stage I), $94.93 \%$ vs $92.39 \%$ (stage II), $73.17 \%$ vs $73.53 \%$ (stage III), $40.63 \%$ vs $36.13 \%$ (stage IV). In the CSS uni-variate risk models, we also saw that for patients in stage I, II, and IV cancers, the unmarried group had a higher risk of dying from PMBC than the married group. Using the married group as a reference, the not married group had a significantly higher risk of cancer-specific mortality: Stage I: (HR = 1.804, 95\% Cl: 1.423-2.286; $P<0.001)$, Stage II: $(\mathrm{HR}=$ $1.758,95 \%$ Cl: 1.389-2.226; $P<0.001)$, Stage IV: $(H R=1.583,95 \%$ Cl: $1.153-2.280 ; P=0.005)$.

\section{Discussions}

PMBC has become a "niche" tumor due to its low incidence, and there are few modern clinical studies on it. Similarly, it also has the characteristics of small tumor size, benign disease variation, low grade, low recurrence rate and high survival rate[8-9,24]. There will be more treasures to be found in his research.On the other side, there have been extensive studies on the effect of marital status on the quality of life of cancer patients, especially breast cancer patients[16, 21, 25-26]. However, in clinical trials and epidemiology, there have been no studies on the effect of marital status on survival outcomes in patients with PMBC.

The purpose of this research is to investigate whether marital status has a significant impact on the survival outcome of PMBC. Through a series of data analysis, it has been found that there are significant differences in OS and CSS between the marrieds and the not marrieds, the married patients can achieve a better survival outcome than the not marrieds. The results indicated that marital status was an independent prognostic factor for the survival of PMBC patients. In addition, for patients older than 45 years of age, or with stage I, II, and IV tumors, the not married people have a significantly higher risk of dying from cancer than the marrieds.

Some studies have suggested that the hysteresis of disease diagnosis is one reason for the poor survival outcomes of the not married patients[17]. Looking deeper, it turns out that for older breast cancer patients, several researchers have proposed that spouses promote positive health behavior (i.e. regular screening and timely medical treatment), which would promote earlier diagnosis[17, 28-29]. Late diagnosis directly affects the survival rate of cancer patients[27]. The PMBC patients in our study were older, with a median age of 68 years old. While the median age of diagnosis for the married and the not married groups was 64 vs 72 years old. Obviously, there were significant differences in the age of diagnosis. The married patients showed a tendency toward earlier and more timely diagnosis than the the not marrieds. 
At the same time, there are also studies that suggested that marital status played a role in the treatment stage of cancer patients, resulting in differences in their survival and prognosis[16]. For patients with inferior marital status, they often need to worry about whether they can bear the economic and social pressure brought by cancer treatment, thus increasing uncertain risk factors in the selection of clinical treatment programs. Previous studies have shown that the not married patients were more likely than married patients to have a longer interval between surgery and radiation and to show lower adherence to treatment, which leading to poorer outcomes[30]. Anan et al. [22] suggested that patients with PMBC, except for those invading the local skin, are suitable candidates for breast-conserving therapy. Yang et al. [24] also considered that adjuvant radiotherapy and endocrine therapy after breast-conservation were recommended for PMBC. From the results of our study, we can find that married patients are more likely to choose breast conserving surgery than the not marrieds in terms of surgical options. And in terms of whether or not to accept radiotherapy, the proportion of married patients and the not marrieds choosing radiotherapy is $54.3 \%$ vs $43.1 \%$. The marital status did influence the choice of surgery and chemotherapy for PMBC patients. Meanwhile, proportional hazards model also proved that patients who didn't choose breast conserving surgery or radiotherapy did have a higher risk of dying from cancer.

More generally, it is believed that the lack of social support and more psychological pressure are the main reasons for the poor survival outcomes of patients with inferior marital status[16, 32]. The impact of psychological distress is more severe in those with cancer than those living with other chronic health conditions[31], and studies also suggest that unmarried adults reported more difficulty adjusting to some aspects of their illness than did married adults. Unmarried patients reported more dysphoric thoughts and feelings (e.g., sadness, reduced self-esteem, body image problems) directly related to their illness than did married patients[32]. In our study, there were also differences in the effect of marital status on survival outcomes of PMBC patients at different ages (Figure 3). For PMBC patients older than 45 years old, the OS survival curve between the two marital states is significantly different. We suspect that for women older than 45 , who are more likely to be in perimenopause or postmenopause, are more likely to produce negative emotions. Study has shown that new onset of depression was also more likely to occur when a woman was peri-or postmenopausal[33]. This also suggests that paying attention to the psychological state of unmarried people with cancer, providing adequate social support and psychological counseling may be an effective treatment direction to deal with the increased risk of death caused by unmarried cancer patients in the future.

However, there are some limitations and problems in our study. First of all, it is possible that some patients cohabited with a partner in the absence of marriage, although the percentage of Americans engaged in such a living arrangement was likely small. In this study, we define them as an the not married population, but in fact, these people have better marital status than unmarried people. Secondly, limited by the SEER database information, we can only obtain the marital status of the included patients at the time of diagnosis. For those whose marital status changed in subsequent stages, it is an unknown factor. Third, prognostic factors associated with marital status that affect patient survival (for example, education, socioeconomic status, and lifestyle) are not included in the SEER database, which bring limitations to our research. Last, our study hypothesize that social and psychological factors may affect 
survival outcomes of unmarried patients, though this can not be validated due to lack of relevant data, but still gives us some hints.

\section{Conclusions}

In summary, by analyzing the information of 14,972 PMBC patients in this study, we found that the risk of death in unmarried patients was significantly higher than that in married patients. The married pure mucinous breast carcinoma patients can obtain better OS and CSS than unmarried patients. Marital status is an independent factor affecting the survival of PMBC patients. We speculate that marital status influences the difference in survival and prognosis of patients by influencing the diagnosis stage, treatment stage and psychological state of patients. The significance of this study is that the not married people in PMBC patients will be a focus target in our clinical treatment, and we should consider investing in targeted social support services and interventions to help reduce significant survival differences between married and unmarried cancer patients paying attention to the psychological state of cancer patients in different marital states will be our future research direction.

\section{Declarations}

\section{Ethics approval and consent to participate}

The study was approved by the ethics committee of Guang Dong Provincial Hospital of Chinese Medicine.

\section{Consent for publication}

Not applicable

\section{Availability of data and materials}

The datasets generated and/or analysed during the current study are available in the [Surveillance, Epidemiology, and End Results (SEER)] repository. (http://seer.cancer.gov)

\section{Competing interests}

The authors declare that they have no conflicts of interest.

\section{Funding}

This study was supported by grants from the Foundation Project of Guangzhou University of Traditional Chinese Medicine (No. XKP2019002); National Natural Science Foundation of China (No. 81904206 and 81974571 ); Guangdong Natural Science Foundation (No. 2017A030313719).

\section{Authors' contributions}


Conception and design: Fan Tang, Xiaoqing Wei, Yuzhu Zhang, Liping Dian; Administrative support: Rui Xu; Liping Ren; Quzhi Zhou; Qianjun Chen; Yuzhu Zhang; Data analysis and interpretation: Fan Tang, Xiaoqing Wei, Yuzhu Zhang, Liping Dian; Manuscript writing: Fan Tang; Final approval of manuscript: all of the authors.

\section{Acknowledgements}

Not applicable

\section{Authors' information}

Fan Tang; Xiaoqing Wei; Liping Dian; Rui Xu; Liping Ren; Quzhi Zhou; Qianjun Chen; Yuzhu Zhang.

\section{References}

[1] Andre S, Cunha F, Bernardo M, et al. Mucinous carcinoma of the breast: a pathologic study of 82 cases. J Surg Oncol 1995;58(3): 162-7.

[2] Berg JW, Hutter RV. Breast cancer. Cancer. 1995;75(1 Suppl):257- 269.

[3] Rosen PP, Lesser ML, Kinne DW. Breast Carcinoma at the extremes of age: a comparison of patients younger than 35 years and older than 75 years. Journal of Surgical Oncology. 1985;28:90-96.

[4] Geschickter CF. Gelatinous mammary cancer. Ann Surg 1938;108: 321-46.

[5] 5Silverberg SG, Kay S, Chitale AR, et al. Colloid carcinoma of the breast. Am J Clin Pathol 1971;55(3):355-63.

[6] Rosen PP. Mucinous carcinoma. In: Rosen PP, editor. Rosen's Breast Pathology. 2nd ed. Philadelphia, PA: Lippincott, 2001, p 463-81.

[7] Pure mucinous carcinoma of the breast Scientific paper. The American Journal of Surgery 187 (2004) $528-532$

[8] Rasmussen BB. Human mucinous breast carcinomas and their lymph node metastases. A histological review of 247 cases. Pathol Res Pract. 1985;180:377-82.

[9] Lee SH, Chaung CR. Mucinous metaplasia of breast carcinoma with macrocystic transformation resembling ovarian mucinous cystadenocarcinoma in a case of synchronous bilateral infiltrating ductal carcinoma. Pathol Int. 2008;58:601-5.

[10] Clayton, F. (1986). Pure mucinous carcinomas of breast: Morphologic features and prognostic correlates. Human Pathology, 17(1), 34-38. 
[11] Rasmussen BB, Rose C, Christensen IB. Prognostic factors in primary mucinous breast carcinoma. Am J Clin Pathol. 1987;87:155-60.

[12] Avisar E, Khan MA, Axelrod D, Oza K. Pure mucinous carci-noma of the breast: a clinicopathologic correlation study. Ann Surg Oncol. 1998;5:447-51.

[13] Di Saverio, S., Gutierrez, J., \& Avisar, E. (2007). A retrospective review with long term follow up of 11,400 cases of pure mucinous breast carcinoma. Breast Cancer Research and Treatment, 111(3), 541547.

[14]Shuning Ding, Jiayi Wu, Caijin Lin, Weiguo Chen, Yafen Li, Kunwei Shen, Li Zhu. Predictors for Survival and Distribution of 21-Gene Recurrence Score in Patients With

Pure Mucinous Breast Cancer: A SEER Population-Based Retrospective Analysis. Clinical Breast Cancer, Vol. 19, No. 1, e66-73.

[15]Ganz P, Desmond K, Leedham B, Rowland J, Meyerowitz B, Belin T. Quality of life in long-term, disease-free survivors of breast cancer: a follow-up. J Nat Cancer Inst 2002;94: 39-49.

[16] Aizer, A. A., Chen, M.-H., McCarthy, E. P., Mendu, M. L., Koo, S., Wilhite, T. J., ... Nguyen, P. L. (2013). Marital Status and Survival in Patients With Cancer. Journal of Clinical Oncology, 31(31), 38693876.

[17] Zhai, Z., Zhang, F., Zheng, Y., Zhou, L., Tian, T., Lin, S., ... Dai, Z. (2019). Effects of marital status on breast cancer survival by age, race, and hormone receptor status: A population-based Study. Cancer Medicine.

[18] Feng, Y., Dai, W., Li, Y., Mo, S., Li, Q., \& Cai, S. (2018). The effect of marital status by age on patients with colorectal cancer over the past decades: a SEER-based analysis. International Journal of Colorectal Disease, 33(8), 1001-1010.

[19] Chen, Z., Cui, J., Dai, W., Yang, H., He, Y., \& Song, X. (2018). Influence of marital status on small intestinal adenocarcinoma survival: an analysis of the Surveillance, Epidemiology, and End Results (SEER) database. Cancer Management and Research, Volume 10, 5667-5676.

[20] Jatoi A, Novotny P , Cassivi S, Clark MM, Midthun D, Patten CA, Sloan J, Y ang P (2007) Does marital status impact survival and quality of life in patients with non-small cell lung cancer? Observations from the mayo clinic lung cancer cohort. Oncologist 12(12):1456-1463.

[21] Osborne C, Ostir GV, Du X, Peek MK, Goodwin JS. The influence of marital status on the stage at diagnosis, treatment, and survival of older women with breast cancer. Breast Cancer Res Treat. 2005;93:41-47. 
[22] Anan K, Mitsuyama S, Tamae K, Nishihara K, Iwashita T, Abe Y, Ihara T, Nakahara S, Katsumoto F, Toyoshima S: Pathological features of mucinous carcinoma of the breast are favourable for breastconserving therapy. Eur J Surg Oncol 2001;27:459-463.

[23] Duggan MA, Anderson WF, Altekruse S, Penberthy L, Sherman ME. The surveillance, epidemiology, and end results (SEER) program and pathology: toward strengthening the critical relationship. Am J Surg Pathol. 2016;40:e94-e102.

[24] Yang, M., Li, X., Pang, C.-H., \& Huang, L.-P. (2013). Pure Mucinous Breast Carcinoma: A Favorable Subtype. Breast Care, 8(1), 56-59. doi:10.1159/000346828

[25] Lilienfeld, A. M. (1956). The relationship of cancer of the female breast to artificial menopause and marital status. Cancer, 9(5),927-934.

[26] Neale, A. V., Tilley, B. C., \& Vernon, S. W. (1986). Marital status, delay in seeking treatment and survival from breast cancer. Social Science \& Medicine, 23(3), 305-312.

[27] Richards, M. A. (2009). The size of the prize for earlier diagnosis of cancer in England. British Journal of Cancer, 101(S2), S125-S129.

[28] Umberson, D. (1992). Gender, marital status and the social control of health behavior. Social Science \& Medicine, 34(8), 907-917.

[29] Steinburg-Schone B, Weinick RM: Health related behaviors and the benefits of marriage for elderly persons. Gerontologist 38: 618- 627, 1998.

[30] Hershman, D. L., Wang, X., McBride, R., Jacobson, J. S., Grann, V. R., \& Neugut, A. I. (2006). Delay in initiating adjuvant radiotherapy following breast conservation surgery and its impact on survival. International Journal of Radiation Oncology*Biology*Physics, 65(5), 1353-1360.

[31] Kaiser, N. C., Hartoonian, N., \& Owen, J. E. (2010). Toward a cancer-specific model of psychological distress: population data from the 2003-2005 National Health Interview Surveys. Journal of Cancer Survivorship, 4(4), 291-302.

[32] Burgess, C., Cornelius, V., Love, S., Graham, J., Richards, M., \& Ramirez, A. (2005). Depression and anxiety in women with early breast cancer: five year observational cohort study. BMJ, 330(7493), 702.

[33] Rodrigue, J. R., \& Park, T. L. (1996). General and illness-specific adjustment to cancer: Relationship to marital status and marital quality. Journal of Psychosomatic Research, 40(1), 29-36.

[34] Ellen W. Freeman, PhD; Mary D. Sammel, ScD; Hui Lin, MS; Deborah B. Nelson, PhD. Associations of Hormones and Menopausal StatusWith Depressed Mood in WomenWith No History of Depression. Arch Gen Psychiatry. 2006;63:375-382. 


\section{Tables}

Table 1. Baseline demographic characteristics of patients stratified by marital status (\%) 


\begin{tabular}{|c|c|c|c|}
\hline Characteristic & $\begin{array}{l}\text { Married } \\
(\mathrm{n}=7462)\end{array}$ & $\begin{array}{l}\text { Not Married } \\
(\mathrm{n}=7510)\end{array}$ & $P$ \\
\hline Age/year & & & 0.000 \\
\hline$\square 35$ & $86(1.2)$ & $101(1.3)$ & \\
\hline $35-44$ & $673(9.0)$ & $399(5.3)$ & \\
\hline $45-54$ & $1308(17.5)$ & $763(10.2)$ & \\
\hline $55-64$ & $1665(22.3)$ & $1136(15.1)$ & \\
\hline $65-74$ & $2125(28.5)$ & $1797(23.9)$ & \\
\hline$\geq 75$ & $1605(21.5)$ & $3314(44.1)$ & \\
\hline Sex & & & 0.010 \\
\hline female & $7421(99.5)$ & $7489(99.7)$ & \\
\hline male & $41(0.5)$ & $21(0.3)$ & \\
\hline Grade & & & 0.020 \\
\hline Well differentiated & $3861(51.7)$ & $3750(49.9)$ & \\
\hline Moderately differentiated & $2153(28.9)$ & $2182(29.1)$ & \\
\hline Poorly differentiated & $285(3.8)$ & $275(3.7)$ & \\
\hline Undifferentiated; anaplastic & $25(0.3)$ & $16(0.2)$ & \\
\hline Unknown & $1138(15.3)$ & $1287(17.1)$ & \\
\hline AJCC 6th Stage & & & 0.000 \\
\hline $\mathrm{I}$ & $5194(69.6)$ & $4703(62.6)$ & \\
\hline II & $2131(28.6)$ & $2548(33.9)$ & \\
\hline III & $41(0.5)$ & $68(0.9)$ & \\
\hline IV & $96(1.3)$ & $191(2.6)$ & \\
\hline AJCC 6th T & & & 0.000 \\
\hline T0 & $1(0.0)$ & $1(0.0)$ & \\
\hline T1 & $5458(73.1)$ & $4906(65.3)$ & \\
\hline $\mathrm{T} 2$ & $1746(23.4)$ & $2087(27.8)$ & \\
\hline T3 & $147(2.0)$ & $292(25)$ & \\
\hline $\mathrm{T} 4$ & $11(0.1)$ & $25(0.3)$ & \\
\hline TX & $3(0.0)$ & $8(0.1)$ & \\
\hline Any T, Mets & $96(1.3)$ & $191(2.5)$ & \\
\hline AJCC 6th N & & & 0.000 \\
\hline N0 & $6832(91.6)$ & $6834(91.0)$ & \\
\hline N1 & $542(7.3)$ & $518(6.9)$ & \\
\hline N2 & $9(0.1)$ & $14(0.2)$ & \\
\hline N3 & $49(0.7)$ & $91(1.2)$ & \\
\hline NX & $30(0.4)$ & $53(0.7)$ & \\
\hline AJCC M & & & 0.000 \\
\hline M0 & $7366(98.7)$ & $7319(97.5)$ & \\
\hline M1 & $98(1.3)$ & $191(2.5)$ & \\
\hline Operation & & & 0.000 \\
\hline BCS & $5032(67.4)$ & $4727(62.9)$ & \\
\hline Mastectomy & $2247(30.1)$ & $2423(32.3)$ & \\
\hline $\mathrm{NO}$ & $183(2.4)$ & $360(4.8)$ & \\
\hline Radiation therapy & & & 0.000 \\
\hline Yes & $4052(54.3)$ & $3236(43.1)$ & \\
\hline No & $3410(45.7)$ & $4274(56.9)$ & \\
\hline Chemotherapy & & & 0.000 \\
\hline Yes & $1142(15.3)$ & $823(11.0)$ & \\
\hline No & $6320(84.7)$ & $6697(89.0)$ & \\
\hline Regional node examined & & & 0.000 \\
\hline 0 & $715(9.6)$ & $1360(18.1)$ & \\
\hline $1-3$ & $3486(46.7)$ & $3114(41.5)$ & \\
\hline $4-9$ & $1681(22.5)$ & $1463(19.5)$ & \\
\hline$\geq 10$ & $1514(20.3)$ & $1502(20.0)$ & \\
\hline Unknown & $66(0.9)$ & $71(0.9)$ & \\
\hline Regional node positive & & & 0.000 \\
\hline 0 & $6178(82.8)$ & $5604(74.6)$ & \\
\hline $1-3$ & $498(6.7)$ & $462(6.2)$ & \\
\hline $4-9$ & $15(0.2)$ & $12(0.2 \square$ & \\
\hline$\geq 10$ & $31(0.4)$ & $42(0.6)$ & \\
\hline Unknown & $740(9.9)$ & $1390(18.5)$ & \\
\hline ER & & & 0.000 \\
\hline Negative & $6776(90.0)$ & $6697(86.2)$ & \\
\hline
\end{tabular}

Page 13/21 


\begin{tabular}{|l|l|l|l|} 
Positive & $157(2.1)$ & $153(2.0)$ & \\
\hline Unknown & $526 \square 7.0 \square$ & $857(8.7)$ & \\
\hline Borderline & $3(0.0 \square$ & $3(0.0)$ & \\
\hline PR & & & 0.050 \\
\hline Negative & $5995(80.3)$ & $5921(78.8)$ & \\
\hline Positive & $795(10.7)$ & $793(10.6)$ & \\
\hline Unknown & $638(8.5)$ & $772(10.3)$ & \\
\hline Borderline & $34(0.5)$ & $24(0.3)$ & \\
\hline Vital status & & & 0.000 \\
\hline Alive & $5915(79.3)$ & $4693(62.5)$ & \\
\hline Dead & $1547(20.7)$ & $2817(37.5)$ & \\
\hline
\end{tabular}

1) Abbreviations: PMBC, Pure mucinous breast carcinoma; AJCC, American Joint Committee on Cancer; BCS, breast-conserving surgery; ER, estrogen receptor; PR, progesterone receptor.

2) All $P$ values comparing characteristics of married and unmarried patients

3) Percentages may not add up to 100 because of rounding.

Table 2. Univariate analysis and multivariate analyses of overall survival of patients with PBMC 


\begin{tabular}{|c|c|c|c|c|c|c|}
\hline \multirow[t]{2}{*}{ Characteristic } & \multicolumn{3}{|c|}{ Univariate analysis } & \multicolumn{3}{|c|}{ Multivariate analysis } \\
\hline & OS HR & $95 \% \mathrm{CI}$ & P value & OS HR & $95 \% \mathrm{CI}$ & $\mathrm{P}$ value \\
\hline \multicolumn{7}{|l|}{ Marital status } \\
\hline Married & Reference & & & Reference & & \\
\hline Not Married & 2.150 & $2.020-2.288$ & 0.000 & 1.363 & $1.277-1.454$ & 0.000 \\
\hline \multicolumn{7}{|l|}{ Age/year } \\
\hline$\square 34$ & Reference & & & Reference & & \\
\hline $35-44$ & 1.347 & $0.676-2.685$ & 0.398 & 1.302 & $0.653-2.597$ & 0.453 \\
\hline $45-54$ & 1.568 & $0.802-3.067$ & 0.189 & 1.620 & $0.828-3.171$ & 0.159 \\
\hline $55-64$ & 2.894 & $1.494-5.604$ & 0.002 & 3.125 & $1.611-6.061$ & 0.001 \\
\hline $65-74$ & 5.562 & $2.932-10.895$ & 0.000 & 6.065 & $3.138-11.724$ & 0.000 \\
\hline$\geq 75$ & 17.391 & $9.038-33.464$ & 0.000 & 14.911 & $7.719-28.804$ & 0.000 \\
\hline \multicolumn{7}{|l|}{ Sex } \\
\hline Women & Reference & & & Reference & & \\
\hline Men & 1.369 & $0.900-2.081$ & 0.142 & 1.545 & $1.013-2.357$ & 0.044 \\
\hline \multicolumn{7}{|l|}{ Grade } \\
\hline Grade I & Reference & & & Reference & & \\
\hline Grade II & 1.019 & $0.948-1.095$ & 0.610 & 1.037 & $0.964-1.116$ & 0.328 \\
\hline Grade III & 1.114 & $0.954-1.300$ & 0.174 & 1.273 & $1.087-1.492$ & 0.003 \\
\hline Grade IV & 1.028 & $0.618-1.708$ & 0.916 & 1.584 & $0.951-2.637$ & 0.077 \\
\hline Unknown & 1.169 & $1.083-1.262$ & 0.000 & 0.972 & $0.897-1.052$ & 0.481 \\
\hline \multicolumn{7}{|l|}{ AJCC 6th Stage } \\
\hline $\mathrm{I}$ & Reference & & & Reference & & \\
\hline II & 1.415 & $1.327-1.508$ & 0.000 & 1.412 & $1.317-1.514$ & 0.000 \\
\hline III & 2.377 & $1.802-3.137$ & 0.000 & 1.273 & $0.820-1.975$ & 0.283 \\
\hline IV & 8.003 & $6.965-9.196$ & 0.000 & 4.112 & $3.443-4.910$ & 0.000 \\
\hline \multicolumn{7}{|l|}{ Operation } \\
\hline BCS & Reference & & & Reference & & \\
\hline Mastectomy & 1.339 & $1.256-1.426$ & 0.000 & 1.045 & $0.962-1.135$ & 0.301 \\
\hline NO/Unknown & 5.987 & $5.324-6.732$ & 0.000 & 1.588 & $1.361-1.854$ & 0.000 \\
\hline \multicolumn{7}{|l|}{$\begin{array}{l}\text { Radiation } \\
\text { therapy }\end{array}$} \\
\hline Yes & Reference & & & Reference & & \\
\hline No & 2.193 & $2.060-2.334$ & 0.000 & 1.471 & $1.362-1.590$ & 0.000 \\
\hline \multicolumn{7}{|l|}{ Chemotherapy } \\
\hline Yes & Reference & & & Reference & & \\
\hline No & 2.023 & $1.814-2.256$ & 0.000 & 0.909 & $0.802-1.030$ & 0.134 \\
\hline \multicolumn{7}{|l|}{ ER } \\
\hline Negative & Reference & & & Reference & & \\
\hline Positive & 1.198 & $0.995-1.443$ & 0.056 & 1.366 & $1.119-1.669$ & 0.002 \\
\hline Unknown & 1.432 & $1.313-1.562$ & 0.000 & 1.081 & $0.879-1.329$ & 0.460 \\
\hline Borderline & 1.277 & $0.412-3.961$ & 0.672 & 0.945 & $0.303-2.948$ & 0.923 \\
\hline
\end{tabular}

Page 15/21 


\begin{tabular}{|c|c|c|c|c|c|c|}
\hline Negative & Reference & & & Reference & & \\
\hline Positive & 1.101 & $1.003-1.208$ & 0.042 & 1.062 & $0.961-1.173$ & 0.237 \\
\hline Unknown & 1.365 & $1.256-1.483$ & 0.000 & 0.997 & $0.820-1.212$ & 0.972 \\
\hline Borderline & 0.968 & 0.624-1.503 & 0.886 & 1.216 & $0.782-1.891$ & 0.420 \\
\hline \multicolumn{7}{|c|}{ Regional nodes examined } \\
\hline 0 & Reference & & & Reference & & \\
\hline $1-3$ & 0.252 & $0.232-0.273$ & 0.000 & 0.604 & $0.354-1.030$ & 0.064 \\
\hline $4-9$ & 0.303 & $0.277-0.331$ & 0.000 & 0.680 & $0.398-1.161$ & 0.158 \\
\hline$\geq 10$ & 0.324 & $0.299-0.352$ & 0.000 & 0.666 & $0.390-1.136$ & 0.136 \\
\hline Unknown & 0.647 & $0.496-0.844$ & 0.000 & 0.873 & $0.578-1.320$ & 0.520 \\
\hline \multicolumn{7}{|c|}{ Regional node positive } \\
\hline 0 & Reference & & & Reference & & \\
\hline $1-3$ & 1.116 & $0.983-1.268$ & 0.090 & 0.938 & $0.816-1.077$ & 0.365 \\
\hline $4-9$ & 1.746 & $0.938-3.248$ & 0.079 & 1.513 & $0.793-2.886$ & 0.209 \\
\hline$\geq 10$ & 2.313 & $1.614-3.315$ & 0.000 & 2.499 & $1.414-4.418$ & 0.002 \\
\hline Unknown & 3.516 & $3.289-3.759$ & 0.000 & 1.095 & $0.644-1.861$ & 0.738 \\
\hline
\end{tabular}

Abbreviations: PMBC, Pure mucinous breast carcinoma; OS, overall survival; AJCC, American Joint Committee on Cancer; BCS, breast-conserving surgery; ER, estrogen receptor; $\mathrm{PR}$, progesterone receptor.

Table 3. Univariate analysis and multivariate analyses of cancer-specific survival of patients with PBMC 


\begin{tabular}{|c|c|c|c|c|c|c|}
\hline \multirow[t]{2}{*}{ Characteristic } & \multicolumn{3}{|c|}{ Univariate analysis } & \multicolumn{3}{|c|}{ Multivariate analysis } \\
\hline & CSS HR & $95 \% \mathrm{CI}$ & P value & CSS HR & $95 \% \mathrm{CI}$ & $\mathrm{P}$ value \\
\hline \multicolumn{7}{|l|}{ Marital status } \\
\hline Married & Reference & & & Reference & & \\
\hline Not Married & 1.942 & $1.681-2.244$ & 0.000 & 1.377 & $1.182-1.603$ & 0.000 \\
\hline \multicolumn{7}{|l|}{ Age/year } \\
\hline$\square 34$ & Reference & & & Reference & & \\
\hline $35-44$ & 1.240 & $0.564-2.725$ & 0.592 & 1.081 & $0.488-2.391$ & 0.848 \\
\hline $45-54$ & 1.073 & $0.497-2.318$ & 0.857 & 1.095 & $0.503-2.386$ & 0.818 \\
\hline $55-64$ & 1.029 & $0.479-2.211$ & 0.941 & 1.223 & $0.564-2.654$ & 0.610 \\
\hline $65-74$ & 1.254 & $0589-2.668$ & 0.558 & 1.799 & $0.834-3.883$ & 0.131 \\
\hline$\geq 75$ & 2.639 & $1.249-5.576$ & 0.011 & 2.902 & $1.347-6.253$ & 0.007 \\
\hline \multicolumn{7}{|l|}{ Sex } \\
\hline Women & Reference & & & Reference & & \\
\hline Men & 2.003 & $0.897-4.472$ & 0.09 & 1.799 & $0.798-4.057$ & 0.157 \\
\hline \multicolumn{7}{|l|}{ Grade } \\
\hline Grade I & Reference & & & Reference & & \\
\hline Grade II & 1.500 & $1.266-1.778$ & 0.000 & 1.215 & $1.022-1.445$ & 0.027 \\
\hline Grade III & 3.479 & $2.703-4.477$ & 0.000 & 1.913 & $1.462-2.504$ & 0.000 \\
\hline Grade IV & 1.530 & $0.491-4.773$ & 0.463 & 1.472 & $0.469-4.618$ & 0.508 \\
\hline Unknown & 1.576 & $1.307-1.901$ & 0.000 & 0.879 & $0.719-1.075$ & 0.210 \\
\hline \multicolumn{7}{|l|}{ AJCC 6th Stage } \\
\hline I & Reference & & & Reference & & \\
\hline II & 2.590 & $2.202-3.046$ & 0.000 & 2.145 & $1.795-2.563$ & 0.000 \\
\hline III & 11.991 & $8.181-17.576$ & 0.000 & 2.741 & $1.27-5.839$ & 0.009 \\
\hline IV & 52.909 & 43.693-64.068 & 0.000 & 18.709 & $14.010-24.984$ & 0.000 \\
\hline \multicolumn{7}{|l|}{ Operation } \\
\hline BCS & Reference & & & Reference & & \\
\hline Mastectomy & 1.953 & $1.670-2.284$ & 0.000 & 1.275 & $1.042-1.560$ & 0.018 \\
\hline NO/Unknown & 20.165 & $16.660-24.407$ & 0.000 & 1.966 & $1.448-2.670$ & 0.000 \\
\hline \multicolumn{7}{|l|}{ Radiation therapy } \\
\hline Yes & Reference & & & Reference & & \\
\hline No & 2.308 & $1.989-2.677$ & 0.000 & 1.252 & $1.039-1.510$ & 0.018 \\
\hline \multicolumn{7}{|l|}{ Chemotherapy } \\
\hline Yes & Reference & & & Reference & & \\
\hline No & 0.531 & $0.451-0.625$ & 0.000 & 0.679 & $0.553-0.834$ & 0.001 \\
\hline \multicolumn{7}{|l|}{ ER } \\
\hline Negative & Reference & & & Reference & & \\
\hline Positive & 2.628 & $1.930-3.579$ & 0.000 & 1.213 & $0.853-1.725$ & 0.282 \\
\hline Unknown & 1.497 & $1.216-1.845$ & 0.000 & 1.297 & $0.770-2.183$ & 0.328 \\
\hline Borderline & 2.542 & 0.357-18.073 & 0.000 & 0.784 & $0.100-6.131$ & 0.817 \\
\hline PR & & & & & & \\
\hline
\end{tabular}




\begin{tabular}{|c|c|c|c|c|c|c|}
\hline Negative & Reference & & & Reference & & \\
\hline Positive & 1.935 & $1.612-2.322$ & 0.000 & 1.554 & $1.269-1.903$ & 0.000 \\
\hline Unknown & 1.509 & $1.234-1.845$ & 0.000 & 0.850 & $0.517-1.399$ & 0.523 \\
\hline Borderline & 1.836 & $0.821-4.106$ & 0.139 & 2.296 & $0.994-5.299$ & 0.052 \\
\hline \multicolumn{7}{|c|}{ Regional nodes examined } \\
\hline 0 & Reference & & & Reference & & \\
\hline $1-3$ & 0.151 & $0.124-0.184$ & 0.000 & 0.218 & $0.087-0.548$ & 0.001 \\
\hline $4-9$ & 0.241 & $0.196-0.296$ & 0.000 & 0.287 & $0.114-0.723$ & 0.008 \\
\hline$\geq 10$ & 0.304 & $0.253-0.364$ & 0.000 & 0.268 & $0.107-0.675$ & 0.005 \\
\hline Unknown & 1.175 & $0.768-1.798$ & 0.458 & 0.654 & $0.389-1.100$ & 0.110 \\
\hline \multicolumn{7}{|c|}{ Regional node positive } \\
\hline 0 & Reference & & & Reference & & \\
\hline $1-3$ & 2.794 & $2.216-3.521$ & 0.000 & 1.103 & $0.851-1.430$ & 0.383 \\
\hline $4-9$ & 7.740 & $3.455-17.342$ & 0.000 & 1.366 & $0.571-3.271$ & 0.484 \\
\hline$\geq 10$ & 12.259 & $8.048-18.675$ & 0.000 & 3.627 & $1.552-8.474$ & 0.003 \\
\hline Unknown & 5.647 & $4.847-6.580$ & 0.000 & 0.567 & $0.228-1.411$ & 0.223 \\
\hline
\end{tabular}

Abbreviations: PMBC, Pure mucinous breast carcinoma; CSS, cancer-specific survival; AJCC, American Joint Committee on Cancer; BCS, breast-conserving surgery; ER, estrogen receptor; PR, progesterone receptor.

Table 4.Univariate analysis of overall survival and cancer-specific survival of PMBC patients with marital status in different cancer stage

\begin{tabular}{|c|c|c|c|c|c|c|c|c|}
\hline \multirow[t]{2}{*}{ aracteristic } & & \multicolumn{3}{|c|}{ Univariate analysis (OS) } & & \multicolumn{3}{|c|}{ Univariate analysis (CSS) } \\
\hline & OS $\%$ & OS HR & $95 \%$ CI & P value & CSS $\%$ & CSS HR & $95 \%$ CI & P value \\
\hline \multicolumn{9}{|l|}{ ige I } \\
\hline rried & $80.80 \%$ & Reference & & & $97.75 \%$ & Reference & & \\
\hline t Married & $65.81 \%$ & 2.072 & $1.914-2.242$ & 0.000 & $96.47 \%$ & 1.804 & $1.423-2.286$ & 0.000 \\
\hline \multicolumn{9}{|l|}{ ige II } \\
\hline rried & $78.18 \%$ & Reference & & & $94.93 \%$ & Reference & & \\
\hline t Married & $59.81 \%$ & 2.197 & $1.968-2.452$ & 0.000 & $92.39 \%$ & 1.758 & $1.389-2.226$ & 0.000 \\
\hline \multicolumn{9}{|l|}{ ige III } \\
\hline rried & $58.54 \%$ & Reference & & & $73.17 \%$ & Reference & & \\
\hline t Married & $50.00 \%$ & 1.292 & $0.720-2.315$ & 0.390 & $73.53 \%$ & 1.019 & 0.481-2.161 & 0.960 \\
\hline \multicolumn{9}{|l|}{ ige IV } \\
\hline rried & $29.17 \%$ & Reference & & & $40.63 \%$ & Reference & & \\
\hline t Married & $20.94 \%$ & 1.656 & $1.239-2.213$ & 0.001 & $36.13 \%$ & 1.583 & $1.153-2.280$ & 0.005 \\
\hline
\end{tabular}

Abbreviations: PMBC, Pure mucinous breast carcinoma; OS, overall survival; CSS, cancer specific survival.

\section{Figures}




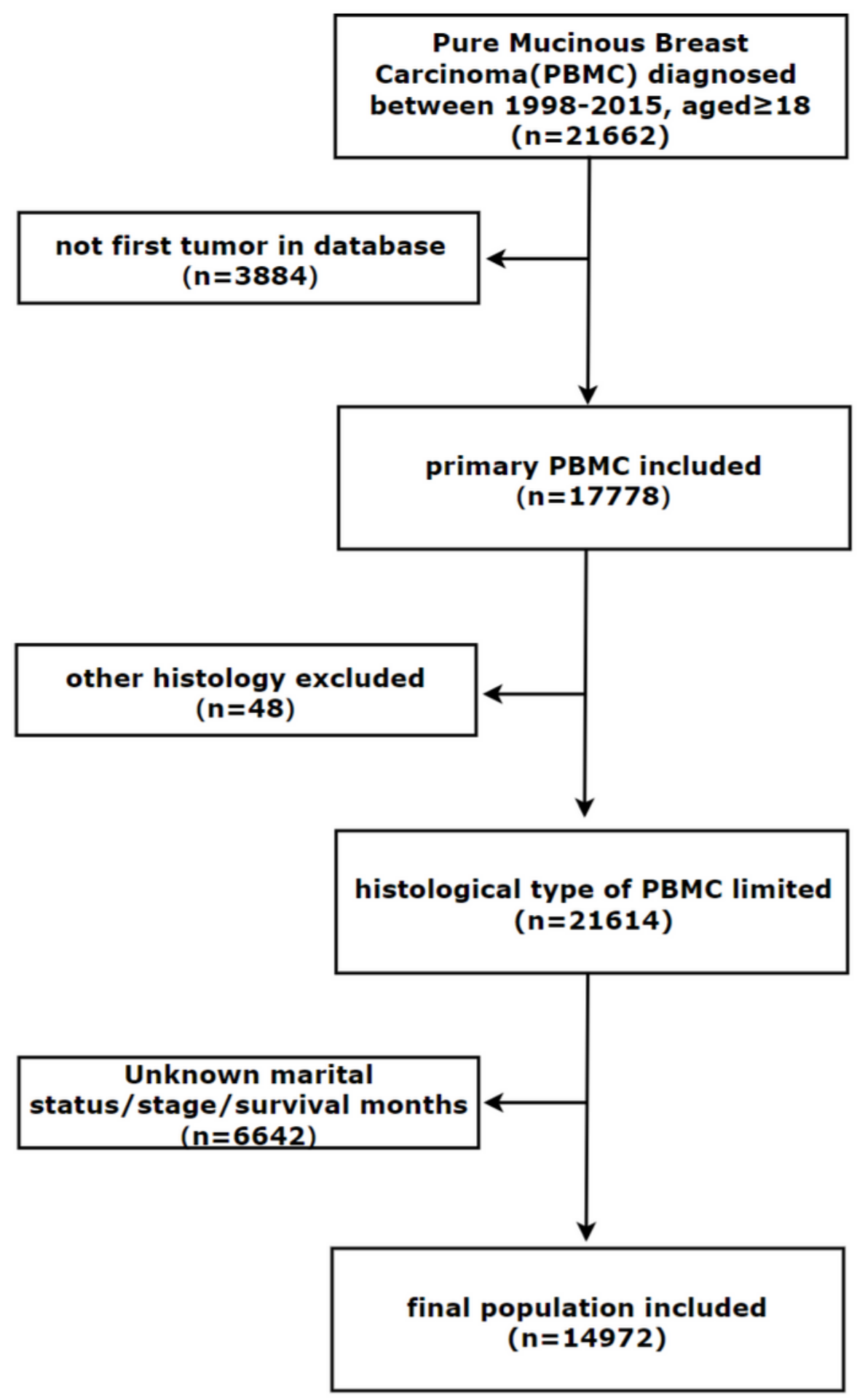

Figure 1

Figure 1

Flowchart for included patients from the SEER database. 
A Overall Survival $(P=0.000)$

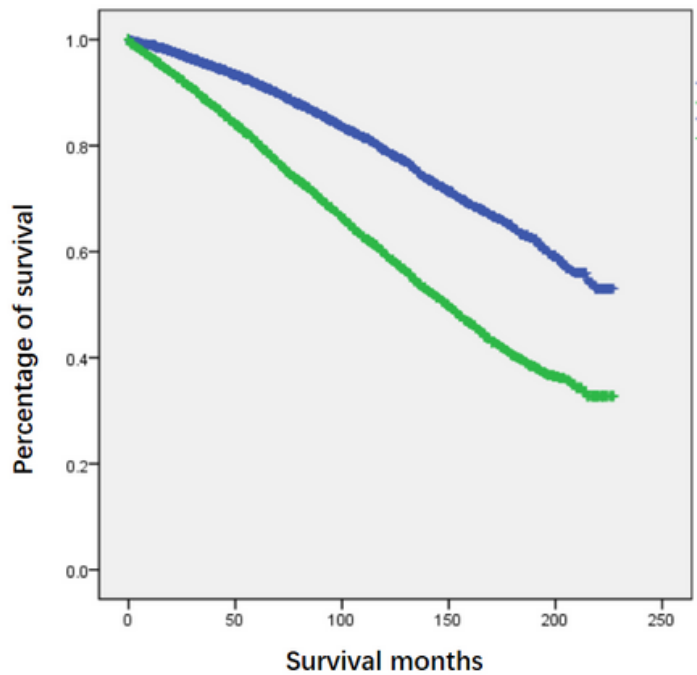

B Cancer Specific Survival $(P=0.000)$

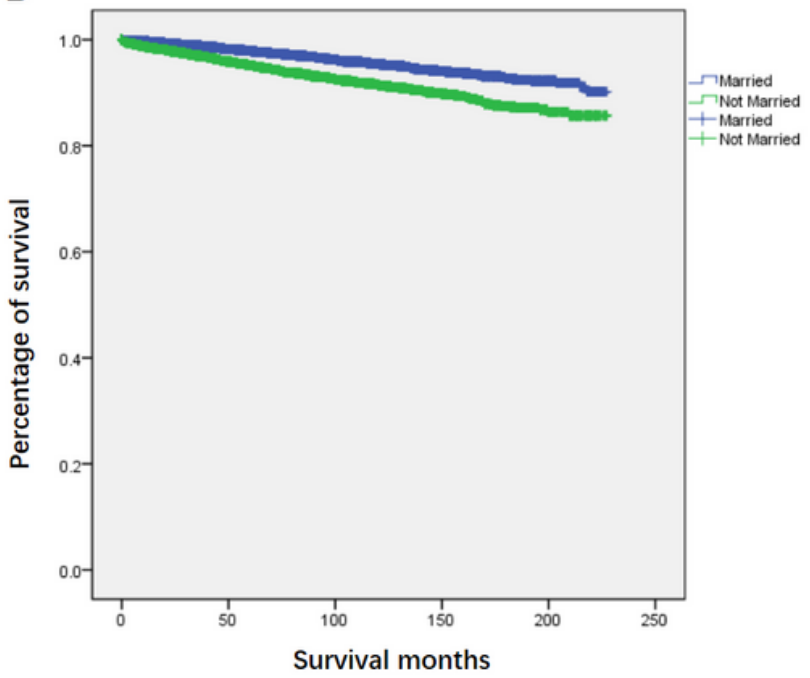

Figure 2

\section{Figure 2}

Kaplan-Meier Survival curves: The overall survival $(A)$ and Cancer-specific survival (B) of patients with pure mucinous breast carcinoma to marital status. $\left.A): \chi^{2}=510.213 P=0.000 ; B\right): \chi^{2}=55.664 P=0.000$.
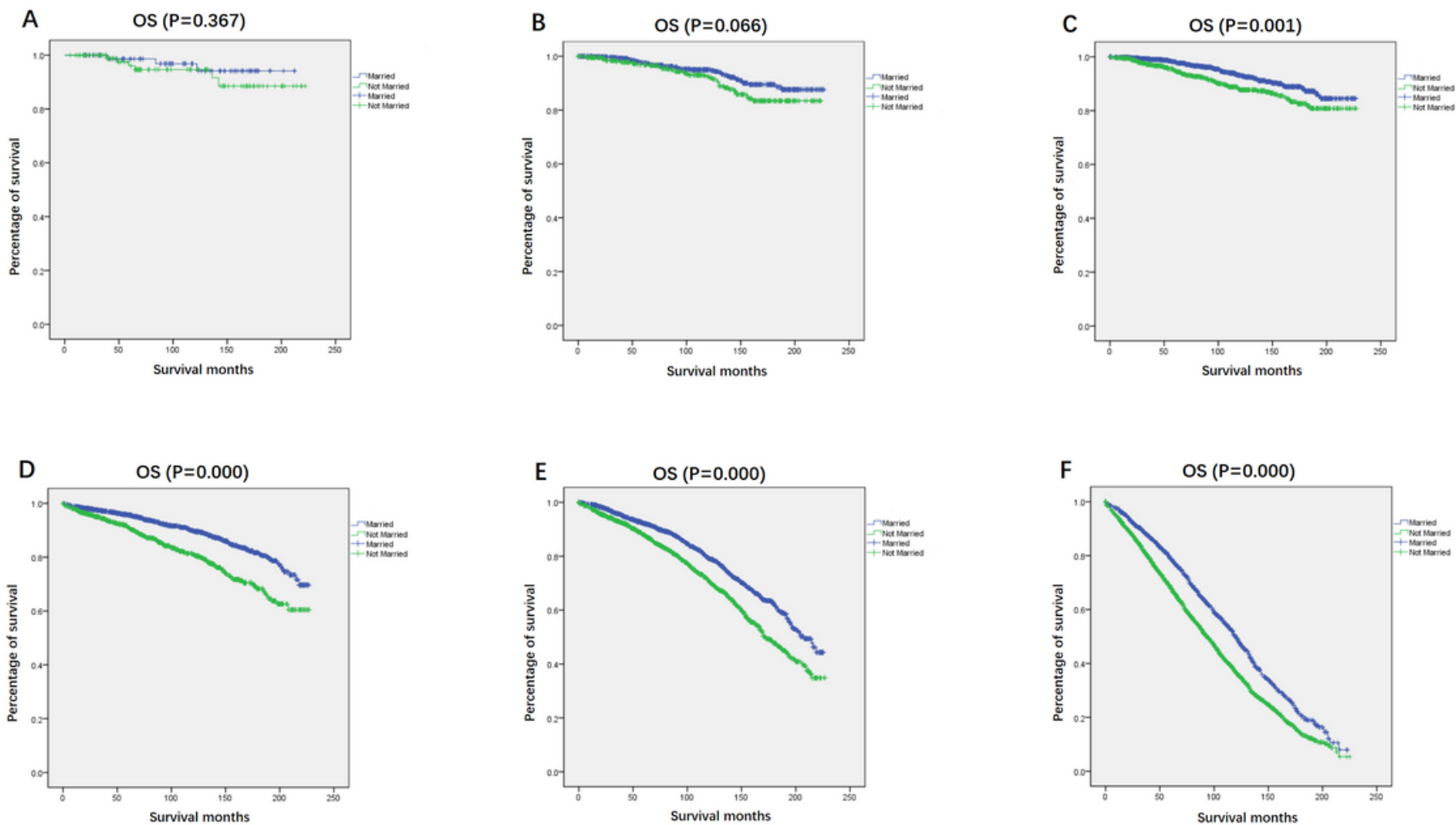

Figure 3

Figure 3 
Analysis of marital status at different stages in age subgroup: Kaplan-Meier Survival curves: The overall survival of patients with pure mucinous breast carcinoma to marital status: A): age: $<35$ years group, $\chi^{2}=0.812 P=0.367 ; B$ ): age: $35-44$ years group, $\left.\chi^{2}=3.386 P=0.066 ; C\right)$ : age: $45-54$ years group, $\chi^{2}=10.402$ $P=0.001 ; D)$ : age: $55-64$ years group, $\chi^{2}=41.422 P=0.000 ; E$ : $65-74$ years group $\chi^{2}=41.319 P=0.000 ; F$ : age $>75$ years old, $\chi^{2}=65.234 P=0.000$. 